\title{
Forward
}

\section{Solving Health Disparities in America One Community at a Time}

\author{
Armin D Weinberg \\ Baylor College of Medicine
}

C) 2007 Californian Journal of Health Promotion. All rights reserved.

In the early days of our country's existence, children were often brought together in one room school houses that provided their basic education. As a civilization, we pushed to the south, north and far west replicating this model. Once there were enough age or ability-matched students, separate sections or classes were inserted and the curriculum changed from reading, writing and arithmetic to include other subjects of societal importance, skills for leadership, and survival. Today, we use technologies to enhance the education and share it with remote regions of our states and territories to include the underserved communities within our major metropolitan areas.

The Summer Workshop, Disparities in Health in America: Working Toward Social Justice was quite the opposite in that it began with the recognition that we exist today in a complex society, struggling with real concrete issues that require a multidisciplinary team approach. Where people of all abilities were clearly linked by our common natural resources, like the air we breathe, or the human fabric we have in common, where disparities in any population can be used to bind us together rather than to pull us apart. This workshop employed faculty from a patchwork quilt of expertise. From young upcoming investigators and professors, to those more senior wishing to pass on their legacy, all those in attendance seem eager to listen and to act.

Furthering our work in the area, it was encouraging to see the variety and mechanisms by which the various contributors have supported their research and demonstration projects. The compliment of federal, state, local and tribal engagement with private and nonprofit sectors confirms that we have crossed the threshold where the elimination of disparities is now seen as a concern for all, rather than for just one segment of the population or a few individuals.

The topics presented in this special edition also help to identify that the nature of the problem is not simply black vs. white, but rather that disparities can be observed in other groups as well and arise from numerous causes such the unacceptable differences in resources, knowledge, access to, and utilization of care, as well as geographic differences, to name just a few.

The papers presented here also reveal an evolving need to address how to increase the application of science to policy and how policy must affect our pursuit of science, where the burden exists. The need for research goes beyond the molecular level to our understanding of how we effectively translate the advances in science into practice and outcomes (Weinberg, 1998).

Back in the days of the old schoolhouse, the teacher might use a riddle to start off a discussion. What do public policy, sex and the environment have in common? Watch it; they were all covered in the course and workshop!

Let's look at a sampling of the lectures from the Summer Workshop included in this special issue for a few examples of what I learned. 
- Moving towards encouraging appropriate cultural and linguistic services, CLAS 2001 (Office of Minority Health, 2001), no longer deems it acceptable to rely on children to serve as interpreters for their parents or grandparents. A corollary, however, is found in the papers by Burhansstipanov and Bemis, where they describe the process and product achieved through Genetic Education for Native Americans (GENA ${ }^{\circledR}$ ) and their workshops. The investigators build on the wisdom of elders who selected their Native college students to be trained, so that they could return to their communities and assist the elders and leaders in making decisions related to genetic research and related issues.

- If you fall and scrape your knee it is easy to see the healing that takes place over time. However the impact of psychological stress is not only hard to see, but harder to measure, especially within the context of our various cultures. In A Little Rain Each Day: Psychological Stress \& Health Disparities, Arthur, brings to our attention that this too must be a part of any equation designed to solve the problems of health disparities today.

- Just as someone might tell you to "listen to your body" when not feeling well, in Behringer and colleagues', Understanding the Challenges of Reducing Cancer in Appalachia: Addressing a Place-Based Health Disparity Population, we learn how important it is to listen to the community itself. Through this community-based participatory study, rural Appalachians meaningfully address the question, "what makes Appalachia different?"

- From a thousand miles away, King examined the perceptions of environmental exposures and associated health effects. Residential Perceptions of Environmental Exposures and Associated Health Effects in the Fresno, Texas Community, demonstrates that community perception can not be dismissed whether in Appalachia or Texas. The challenge also involves engaging communities to incorporate the data and science into their resolutions of the problems at hand.

- Ameliorating the disparities will require the participation of those we are trying to reach. In Cole's, Black Women and Sickle Cell Disease: Implications for Mental Health Disparities Research, I am reminded of an old adage my father shared many times; "one third of the population had physical problems, one third mental and the final third have both!" The most important message in the paper, however, is that she thanked all of the women who participated in this study. For without such participation, we would not be able to demonstrate that eliminating disparities in participation in clinical research of all types is possible.

- Star Wars or Star Trek? Clearly the future is closer than I thought. Bezold's, Biomonitoring and Health Disparities Emerging Opportunities, persuasively links our elimination of disparities to our ability to harness technology that is at hand or soon will be.

- A standard look at common data might take us down an incorrect path, one that we might design an intervention around, one perhaps doomed to failure. The paper by Gor et al., Cancer Screening Practices Among Chinese and Vietnamese in the Greater Houston Area, reminds us that we need to challenge what may be considered "general knowledge." The message here, we better look just a little harder and a little deeper into our understanding of the differences within populations and within communities.

- In Race, Skin Color and Genetic Ancestry: Implications for Biomedical Research on Health Disparities, Kittles and colleagues discuss why using race in biomedical studies is problematic based on examples from two U.S. groups (African and Hispanic Americans) which transcend 'racial' boundaries and bear the burden of health disparities. This squarely places the requisite 
discussion about such issues where it belongs, i.e., "the ball is now in our court!"

- Hernández-Valero and her colleagues, illustrate how modern science and social science can be brought to bear on an old problem. Gene-Environment Interaction Research Addressing Environmental Justice among Migrant and Seasonal Farmworker Women and Children in Texas employs a multidisciplinary approach weaving an ongoing molecular epidemiological study, based on community-based participatory research (CBPR) approaches as well as gene-environment interaction research to address environmental justice.

- McArthur and Dacso's paper, Submaximal Decision Theory and Health Resource Conservation uses the example of chronic heart failure (CHF) to illustrate an approach to understanding the complexity of chronic illness in underserved communities. The authors offer that solutions are possible and that strategies are available to clinicians and patients.

- Often our definition of health disparities quickly focuses our reference to racial and ethnic groups. Nosek and Simmon's report, Sexual and Reproductive Health Disparities Experienced by People with Disabilities: Myth versus Reality brings a fresh and valuable reminder that disparities go well beyond the question of race, ethnicity, or socioeconomic status.

- Casari Stone and colleagues discuss the Latino health paradox and suggest policy and prevention strategies for promoting the health of the largest emerging minority group in the U.S. in Socio-Economic and Health System Threats to Latino Health: Implications for Policy and Prevention. She also enlightens the reader by explaining the use of the terms Latino and Hispanic within the context of her paper. Thank you, from those who are always struggling, it is reassuring to have this defined for the reader. [Note: While the construct of Latino has complex meaning (social and political) and is more inclusive than Hispanic, we will be using both words interchangeably in this paper. Hispanic will be used when presenting data from studies and Latino will be used to include all racial and ethnic subgroups residing in the U.S., e.g., Mexican, Chicano, Puerto Rican (mainland and island), Cuban, and Central and South Americans.

- Jackson's analyses identify specific microethnic groups within a region of Africa that may be the sources of relevant polymorphisms contributing to the etiology of aggressive prostate cancer in the Chesapeake Bay. This report, Ancestral links of Chesapeake Bay region African Americans to specific Bight of Bonny suggests a historical link between specific African microethnic groups and a U.S. health disparity. Our attention to understanding the root of such differences really perks everyone's interest in our quest to understand our history and search for identity.

- Philips and colleagues describe an innovative community-based project using the Community Health Improvement Process Model to create a meaningful and important cancer awareness network and cancer plan in a tri-ethnic rural county of Texas suffering from the second highest overall cancer mortality in Texas. While sharing the story of this comprehensive, inspirational project, the authors also remind us of the challenges faced by those working hard to make translational medicine a reality in academic institutions.

The educational objectives of the Summer Workshop and the evaluation by the participants or "course-goers" clearly support that there is benefit to those who have participated. The future, however, lies in the impact of those who return to work, or to their neighborhoods, and apply something gained from the workshop.

Among the recommendations from those in attendance was the identification of future specific topics and speakers, such as those from 
specific ethnic groups. Although including additional groups is clearly a part of moving forward, so too is the challenge faced by the course director and faculty who strive to teach that there are common threads that exist both within and across populations that experience health disparities - a theme that should be "self-evident." In doing so, the strength of the lessons learned in such a dynamic course or workshop should be readily translated or transferred to those serving populations who suffer inequities in health.

Katrina may have turned over the rock, but the problems were there before the disaster. Solutions will need to recognize this fact as well as the current failures in the system. Old policy doesn't make good policy, and in fact, undoing bad policy will also be part of the solution. Likewise, maybe the time has come to declare victory in some areas, and move on to other things that we together must attend to, if disparities among any population remain.

If indeed the reform we expect in the health care system unfolds, we should prepare those in attendance in the future and those that are "alumnus", to seek and quickly learn how proposed and real changes will impact the disparities we know today. Some may forecast a worsening, while others a significant improvement. Take for example the utilization of preventive services in systems where cost is not an issue. Have those resulted in $100 \%$ participation?

These thoughts beg the question, what is the bottom line? I would suggest that as we have unraveled the mystery of the genome, we must now unravel the mystery of disparities. As the Genome Project, provided us with a map, not the directions, so too must be our identification of the root causes of disparities be viewed as our map. If as many believe we are on the verge of realizing the benefits of personalized medicine, based in large part on our genetic makeup, then what most also acknowledge is that we are quickly realizing that gene-environment interactions as well as other variables still make our quest one individual at a time. Likewise, to eliminate disparities, we must recognize that it will be one community, one institution, one organization or one population at a time. Each has different politics, resources, leadership, and economies, comparable to the diverse GeneEnvironment interactions, and these become the equivalent to Disparity - Community Interactions. So let us agree we can solve health disparities one community at a time.

In only a few short years, this Summer Workshop has successfully galvanized a core of fundamental topics to conquer health disparities, around which new and evolving issues can be addressed. The central theme of disparities in America recognizes that if we focus on resolving our own, we can learn from connections with our heritage, genetic path, cultural adaptations, and geographic influences, and in fact help those who remain from whence we've come! This, I believe, is the next step in the Workshop's evolution. Bringing solutions from our community to yours, regardless of where on this wonderful planet called Earth you live.

\section{References}

Office of Minority Health. (2001). National standards for culturally linguistically appropriate services in health care (final report). Washington, DC: US Department of Health and Human Services. Retrieved May 1, 2007, from http://www.omhrc.gov/assets/pdf/checked/finalreport.pdf

Weinberg, A. D. (1998). People Need Policy and Policies Need People. Cancer, 83 (8 Suppl.), 16911695. 
$\underline{\text { Author Information }}$

Armin D Weinberg, PhD

Professor of Medicine

Baylor College of Medicine

* corresponding author 